Cynulliad Cenedlaethol Cymru The National Assembly for Wales

Education and Life-Long Learning Committee

Final Report:

\title{
Information and Communication Technology in Education
}


Further copies of this document are available from:

Gareth Woodhead

National Assembly for Wales

Cardiff Bay

Cardiff

CF99 1NA

Tel: 02920898618

Fax: 02920898021

e-mail: gareth.woodhead@wales.gsi.gov.uk 


\section{Contents}

$\begin{array}{ll}\text { Foreword } & 1\end{array}$

Introduction 3

Chapter 1: $\quad 5$

Background to Report

$\begin{array}{ll}\text { Chapter 2: } & 10\end{array}$

The Experience of Other Countries

$\begin{array}{ll}\text { Chapter 3: } & 12\end{array}$

Committee's Consideration and Conclusion

$\begin{array}{ll}\text { Chapter 4: } & 20\end{array}$

Funding

$\begin{array}{ll}\text { Chapter 5: } & 21\end{array}$

Monitoring and Evaluation

Chapter 6:

22

Conclusion

Annex A 



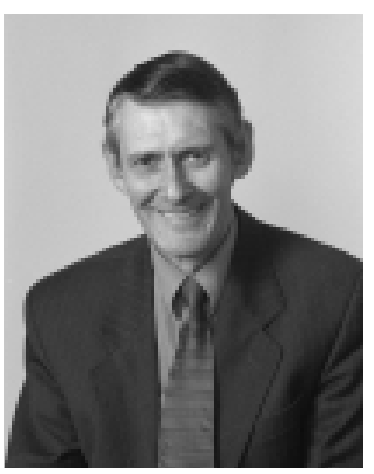

\section{Foreword}

This is a key policy initiative, developing a national educational strategy for Wales in the area of information and communication technology. The Committee has said on many occasions that it does not see the development and delivery of a national information and communication strategy as a matter of choice but as a matter of necessity.

Education underpins everything that we achieve as individuals and together as a community. In order to give our children, our future, the best start in life we must make sure that we provide them with the highest quality of educational opportunities. The information and communication technology strategy will be a valuable contribution to this. The benefits that children and young people will reap from this will give them the firm foundation upon which they will be able to compete for high quality highly paid jobs.

If we have the people with skills then the National Economic Strategy for Wales will have a sound platform on which to build economic enterprise and wealth. Not only should it be possible to attract high calibre companies to Wales but it should also provide the skills base for young people to become the entrepreneurs of the future. It brings the links between education and training closer, leading to greater flexibility in its delivery and supporting individualised forms of learning and accreditation.

The Committee sees as a fundamental issue the need to establish a culture of using information and communications technologies in schools to raise educational standards. It is also part of the continuum of education and training and should not be seen in isolation from the further and higher education sectors nor from the opportunities for life-long learning. It is essential that those sectors look at what is happening in our schools and build and support that in their own areas.

I would like to thank Huw Lewis and Jonathan Morgan on behalf of the Committee for the work they have put into this review. They accepted the role of leading on it and undertook that task diligently on the Committee's behalf.

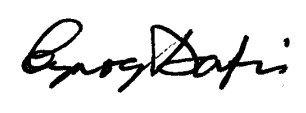

Cynog Dafis AM

Chair to the Committee 



\section{Introduction}

The Education and Life-Long Learning Committee is established under the Government of Wales Act 1998 and Standing Order 9. Its remit covers education and life-long learning, this includes, amongst other things, the national curriculum and qualifications, all aspects of schools administration and organisation, further and higher education, supply side employment policy, including the New Deal and the work of the employment service, career services and work related training. The Committee took over this policy review from the previously established Pre 16 Education, Schools and Early Learning Committee in November 2000.

The Assembly Minister who has responsibility for this area of work is Jane Davidson A.M.

The Committee's membership is:

$\begin{array}{lll}\text { Lorraine Barrett } & \text { Labour } & \text { Cardiff South and Penarth } \\ \text { Cynog Dafis (Chair) } & \text { Plaid Cymru } & \text { Mid and West Wales } \\ \text { Jane Davidson (Assembly Minister) } & \text { Labour } & \text { Pontypridd } \\ \text { Janice Gregory } & \text { Labour } & \text { Ogmore } \\ \text { Christine Humphreys } & \text { Liberal Democrats } & \text { North Wales } \\ \text { Pauline Jarman } & \text { Plaid Cymru } & \text { South Wales Central } \\ \text { Gareth Jones } & \text { Plaid Cymru } & \text { Conwy } \\ \text { Huw Lewis } & \text { Labour } & \text { Merthyr Tydfil and } \\ & & \text { Rhymney } \\ \text { Jonathan Morgan } & \text { Conservative } & \text { South Wales Central } \\ \text { Alun Pugh } & \text { Labour } & \text { Clwyd West }\end{array}$





\section{Chapter 1: Background to Report}

\section{Remit of the Policy Review}

The Committee began this policy review by focusing on the local education authority (LEA) procurement of Information and Communication Technology (ICT) for schools, however while gathering information from organisations it became clear that the remit needed to be widened. The remit for stage 1 was agreed by the Committee at its meeting on 14th July 1999 and revised to include stage 2 at its meeting on 12th April 2000 (PRE 16 05-00). The full remit is set out below:

\section{Stage 1}

To investigate the development of the National Grid for Learning (NGfL) in Wales with a view to:

i. Reviewing progress towards the target of linking all schools to the Grid by 2002;

ii. Considering the scope for greater co-operation between LEAs as they develop their own learning networks with a particular focus on joint procurement; and

iii. To consider the need for further specialist guidance to LEAs on the most effective networking solutions for schools.

\section{Stage 2}

To take forward the findings of stage 1 by:

i. An examination of the merits of developing a National Framework Agreement to support procurement so as to achieve economies of scale;

ii. An investigation as to why the NGFL managed service do not meet the needs of Welsh LEAs and explore with Association of Directors of Education Wales (ADEW) ways in which this could be improved;

iii. An exploration with ADEW, Qualification Curriculum and Assessment Authority for Wales (ACCAC) and other interested parties as to whether the establishment of a National ICT network based in the public sector is feasible for Wales, and the implications in time and resources of establishing such a network; 
iv. An examination of ways to establish greater co-operation across Wales in the development of bilingual educational software that supports the national curriculum;

v. A review of the delivery of training in ICT for teachers in Wales and the support available to them on the use of ICT in delivering the national curriculum; and

vi. Examining the merits of creating a NGfL, Wales team to develop and maintain the NGfL website in Wales that meets the needs of teachers in Wales.

\section{Consultation}

The Committee began its review by consulting with all LEAs in Wales through their Directors of Education and Information Technology Advisors. Copies of the responses received can be accessed at www.wales.gov.uk under Pre 16 Education, Schools and Early Learning Committee for the meeting on 15th December as paper PRE 16 10-99 (p.5) together with a summary of the responses. The written responses were supported by a number of oral presentations to the Committee, which are recorded in the Committee's minutes. This consultation focused on four key issues:

- reviewing progress towards the target of linking all schools to the grid by 2002;

- considering the scope for greater co-operation between LEAs as they develop their own learning networks with a particular focus on joint procurement;

- considering the need for further specialist guidance to LEAs on the most effective networking solutions for schools; and

- considering the extent to which schools and LEAs in Wales will be investing in National Grid for Learning managed services and, where they are not doing so, what plans are in place for schools to be supplied with an equivalent service.

It became clear that there was a lack of common vision and direction in introducing and using ICT in schools across Wales, not least at LEA level. However, the Committee was heartened by the general acknowledgement that there was a need for a national strategy with strong leadership by the National Assembly. In this context it welcomed the publication of the prospectus 'ICT for Learning'. 
There were concerns for the three elements of connectivity - the network needed to support the strategy and the personal computers needed for teachers and pupils to use; competency - the training needs of the teaching staff, technical support and the level skill that pupils should be achieving; and content - what was available for teachers and pupils to use to support their professional development and curriculum studies in both the Welsh and English languages. The Committee agreed at this stage to widen the scope of its review and invited Huw Lewis A.M. and Jonathan Morgan A.M. to lead on it.

The Committee also decided that an expert adviser should be appointed to assist Huw Lewis and Jonathan Morgan in their work.

\section{Expert Adviser}

After an open competition, Neil Harries, the retired Director of Education for Caerphilly Borough Council was appointed as the Committee's Expert Adviser on ICT in Schools.

\section{Principles}

The Committee agreed that the ICT strategy should be based on the following principles:

- all pupils have an equal right to knowledge about and familiarity with ICT through the education system, this pre-supposes that pupils must have access to technology;

- that the personal computer in the classroom must be an integral part of the tuition system for all;

- that teaching methods will be adapted to facilitate this and that pupils will be afforded sufficient access; and that

- schools must provide the individual pupil with the capacity to develop competencies throughout life, as part of life-long learning.

\section{Objectives of the Strategy}

By adopting these principles the ICT Strategy should ensure that:

- all pupils have equitable access to ICT;

- all pupils will leave school with the technology skills needed in today's world and tomorrow's workplace; 
- all teachers will be properly equipped to use technology as a tool to achieve high academic standards;

- the needs of both Welsh and English languages are properly met;

- all parents and communities are kept informed of key decisions in the teaching of ICT in schools; and

- that Wales invests in the development of educational software for its schools, with the support of research and development.

The Committee was also aware during its consideration of other strategies and reports that considered the need in Wales for skills development especially in information and communication technology. In particular it made reference to the National Economic Development Strategy which calls for the creation of a high-skill, high-value added economy that will increase GDP and help bridge the wealth gap within Wales and between Wales and the rest of the United Kingdom. Skills development is seen as having a crucial part to play in moving Wales firmly into the knowledge-based economy. The vision the National Economic Development Strategy has for Wales is 'A prosperous Welsh economy for the 27st century that is dynamic, inclusive and sustainable, based on world-class competitive business and skilled, motivated people.

The ICT in Schools strategy will contribute to this vision by ensuring that pupils have the ICT skills that are needed to enable them to contribute to develop in Wales a highly skilled, world class economy.

The Wales Skills Task Force was set up to take a strategic overview of the implications of the Future Skills Wales findings and make recommendations to the National Assembly for skills development. One of the Task Forces' key findings was that ICT 'will inevitably be an increasing feature in skills development; as necessary skills in their own right and as a medium through which we learn. Wales needs to make more effort in this area.'

The Task Force made two key recommendations which are directly relevant to this strategy under the section 'Providing the Skills to succeed in the Labour Market improving the content of education and training provision'. They are: 
- to continue and extend efforts to ensure that all of our young people are mastering the skills of literacy and numeracy and ICT; and

- a continuing programme of teacher training, professional development and support materials to support the delivery of key skills in the curriculum and in work based training.

Estyn through its inspection programme has been able to make a comprehensive assessment on an annual basis of the teaching and learning of ICT skills throughout the curriculum as delivered in schools. In their annual report for 2000 they presented hard evidence to support their conclusion that there was a need to accelerate progress in the introduction of ICT across the curriculum. Factors that affect this development include:

- not enough whole-school planning for using ICT across the curriculum;

- lack of awareness within subject departments about how ICT can be used effectively; and

- issues related to resources, classroom management and teachers' own skills in using ICT. 


\section{Chapter 2: The Experience of Others}

Huw Lewis and Jonathan Morgan undertook visits to the Scottish Council for Education Technology (SCET), Department of Education and Science (DES) in Ireland and the British Educational Communications and Technology Agency (BECTA) in England to hear at first hand how they had developed their ICT strategies. A full report of the visit to SCET was made to the Committee at its meeting on 12th April and a written report was presented as paper PRE 16 06-00(p.3) which is available on the Committee's web page.

Reports on the visit to BECTA and to DES are also available on the Committee's web page.

SCET was a strong force in ensuring ICT was integrated throughout the curriculum in Scotland. It worked closely with the National Curriculum Council in Scotland and in July 2000 the two bodies merged into Learning and Teaching Scotland. SCET developed a successful commercial business by selling its software developments across Scotland and developing world-wide links with software houses. Learning and Teaching Scotland is an innovative organisation which continues to be supported by the Scottish Executive in order to ensure that pupils and students in Scotland are well equipped with the skills necessary to attract high quality jobs to Scotland.

The visit to BECTA clarified what its role was in relation to Wales. Essentially, it has provided technical and procurement expertise 'on demand'. This has been valuable in its way. However, the Committee felt that it did not possess the critical mass to develop its knowledge of Wales or focus attention on the country's need to drive forward the integration of ICT in schools for the way ahead. It was felt that this next stage needed to be addressed on a still stronger and more systematic basis in Wales, drawing on the resources of BECTA as required and where appropriate.

The visit to DES showed what was possible if a strategic approach was taken and driven at a national level with sufficient funding being provided to deliver in key areas. It also recognised the need for a body to be identified that would be responsible for driving forward the strategy that needed to be developed and delivered in Wales.

In addition, the Expert Adviser examined the experiences in other countries, primarily, the United States of America, New Zealand and the Scandinavian countries. Consideration of the experiences of these countries is included in his report to the Committee. 
The Committee took a number of key messages from these experiences including:

- The need to ensure that there is a high skilled work force that will attract high quality and high paid jobs starts in schools and colleges. If this foundation is not established and supported young people will be denied an opportunity to compete in today's economy. This will, of course, be reflected in the performance of the Welsh economy.

- Countries which had successfully introduced ICT in schools had done so in a planned and strategic way, well supported with equipment, trained teachers and technicians. Bodies such as SCET, National Centre for Technology in Education, Ireland and the Chief Executive Officers Group in America are good examples of groups formed to lead on such strategies.

- The private sector has a vested interest in ensuring that ICT strategies are introduced in schools and are working. Pupils and students are their future workforce and they therefore need to support the investment in this strategy. The most successful ICT strategies in education are in countries where the private sector, especially the telecommunication sector, have taken an active role.

- The ICT sector is a fast moving one and to delay investing in this key skill not only means that Wales will be left behind but that the gap will widen at an ever increasing rate which may prove impossible to close.

Countries who have correctly perceived that the development of ICT skills in schools is a key driver in the economic regeneration of their countries have made a commitment to invest in this area and are now seeing the benefits. This includes countries such as Ireland, New Zealand, Finland, Singapore and the United States of America.

The Committee concluded that Wales should make a similar commitment and that this strategy should be seen as a key platform to establishing that commitment in practical terms. 


\section{Chapter 3: Committee's Consideration and Conclusion}

Neil Harries was given the task of reviewing all the information that had been collected through the consultation and the visits to SCET, DES and BECTA. In addition, he reviewed some of the evidence on how other countries had developed their own national strategies and implemented them. Among other things he looked at experience in California, USA, Israel, Scandinavian countries and New Zealand. He identified that all these countries had had common problems such as hardware, compatibility, skills levels of teachers and the need to provide good quality materials.

He concluded that the strategy had to have three central legs to support it: connectivity, content and competence.

The Expert Adviser's draft report was discussed at a conference on 29th September, 2000 which brought together a broad range of educationalists and IT advisers working in the education field. The conference gave an opportunity to all of these practitioners to contribute and consider the detail of the strategy and to comment on its relevance to education in Wales and its practicability. As a consequence of their comments Neil Harries refined his report further. This final report was endorsed by Huw Lewis and Jonathan Morgan and presented to the Committee for its consideration on 8th November, 2000. The final report can be accessed on the Education and Life-Long Learning Committee's web page at www.wales.gov.uk .

At its meeting on 8th November the Committee considered the Expert Adviser's report and agreed that the recommendations taken as a whole should be seen as the 'vision' as to where ICT in schools should be by the year 2010. However, they also placed the caveat on this that the rapid progress being made in technologies should be monitored and the strategy amended as required, in line with available resources, to keep it as current and relevant to education as was possible.

In accepting the recommendations as a whole the Committee specifically recommended that action should be taken urgently to establish:

- an Advisory Panel for ICT in Schools with a precise 3-year development brief for ICT in schools in Wales;

- an Information and Communications Technology Task Force (Task Force) as an arm's length team to carry out the 3-year development programme for ICT in schools; and 
- a National Grid for Learning, Cymru (NGfL, Cymru) to provide all appropriate curriculum services, planned, designed and tailored to the needs of Welsh Schools, working in both English and Welsh languages.

The Committee stated that it would wish to see a constructive and positive start made before Easter 2001 to establish these bodies. Collectively they would spear head the introduction of the strategy in Wales and ensure that it moved forward in the right direction at the right pace. A suggested remit for each of the bodies is contained in Annex A, together with a suggested organisational chart demonstrating the relationship of the three bodies.

The Committee further recommended that a system for capturing and evaluating accurate and relevant data on ICT equipment in schools in Wales be established. It accepted that much of this information was already available in a number of forms and locations. However, it felt that it was important that this information be brought together and held centrally possibly by the Task Force which could update it on a regular basis. This information was a necessity in order that realistic funding assessments and realistic action plans could be made. Once this initial data gathering exercise was complete arrangements for an audit of ICT equipment in schools should be put in place so that the Advisory Panel, and the, Task Force could undertake their work with the support of accurate and up to date data.

The Committee's consideration and recommendations have been categorised in to the three themes under which they were considered.

\section{Connectivity}

While the outcome of the audit will help identify what needs to be done, the Committee recognised that firm objectives of the strategy should be subject to further consideration, consultation and research by the Advisory Panel. However it agreed that the provisional aim of the strategy in terms of connectivity should be to:

- ensure the existence of full Curriculum Networks in all LEAs within 3 years;

- ensure the existence of School-wide Networks with a minimum of 5 'drop points' per classroom in all schools in Wales in 3 years;

- establish a minimum standard ratio of 1 multi-media Personal Computer (PC) to every 5 pupils in 3 years; and

- initiate an ICT equipment replacement programme for schools from the 3rd year of the development. 
The Committee accepts that the burden of meeting these recommendations falls in the main to the local education authorities. It recommends that the Task Force should take the lead working with LEAs to develop implementation plans with costings. This information can then be used to ensure that, taking account of available resources, funding is deployed and targeted to achieve the strategy's aims for connectivity progressively.

In order to ensure best value for money the Committee concluded that economies of scale could be achieved through LEAs working collectively in procuring ICT equipment. The Committee recommends that the Task Force be charged with investigating in detail the best way of achieving economies of scale in the purchase of ICT equipment for schools, including the possibility of developing a national procurement agreement. If the Task Force concludes that the best way forward would be by action on a collective basis, then any necessary legislative arrangements should be made for the purpose.

It is essential that there is an open and sustained discussion at a national level about establishing and evaluating public/private partnerships. There must be a clear understanding on both sides on what is meant by partnerships and what their objectives are. The Task Force should lead this. This is also essential to ensure that new ICT products and changes in education complement each other.

The Committee received information about personal computer re-cycling operations in New Zealand and America. While the Committee accepted that schools should be provided with the most up to date equipment for pupils, it felt that on a complimentary basis there was sufficient merit in these schemes to warrant further exploration. The Committee recommends that the Task Force explores further the merits of establishing a franchised personal computer re-cycling operation for schools. The Task Force could usefully discuss this with organisations that currently have experience in running such schemes.

The building of an ICT network across schools is important and this will be an integral part of the National Assembly for Wales' Information Age Strategy. The need for the National Assembly to take a lead in developing the vision of an 'Information Age Wales' has already been identified and acted upon. Work is underway to develop an overarching Information Age strategic framework and supporting programme of activities. This will need to build on the work already going on in the various sectors, including education, but will also need to ensure that unnecessary duplication is reduced. Four main areas are being pursued (although there will be many related activities). These reflect a more holistic approach to ensuring that Wales will benefit from the social and economic opportunities ICT offers. 
There are also other educational networks that schools may wish to consider linking to, for example the Joint Academic Network (JANET) which links all universities and colleges in the UK, and with funding support from the Further Education Funding Council Wales which was extended to all further education colleges some 5 years ago. The Committee recommends that the possibility of further extending this network to sixth form colleges and to schools with sixth forms should be considered by the Task Force.

In the same vein so as to improve links across sixth forms and support the delivery of the 'A' level syllabus introduced in September 2000, the Committee recommends that video-conferencing facilities are installed in every secondary school with a sixth form and in sixth form colleges. The Committee understands that this facility is being installed in all Further Education Colleges in Wales. The integration of sixth forms into this provision will greatly assist with the teaching of small groups and minority subjects in the post 16 curriculum.

In a majority of the presentations made to the Committee the one issue that it was urged not to overlook was the need for adequate well-qualified technical support in schools. The provision of equipment was one issue but maintaining and repairing it also needed to be built into the strategy. Experience from other countries supported this view. The Committee recommends that the Task Force be invited to consider this further and issue guidance on how LEAs could ensure the appropriate level of maintenance and support for ICT equipment in schools by the end of 2001.

\section{Competence}

Estyn has already begun the work of conducting surveys of ICT in Initial Teacher Training (ITT) in Higher Education institutions and partner colleges. Its main findings have indicated that the quality of college based training and assessment in ICT is variable within and between Higher Education Institutions, it found that 'overall there is insufficient attention to ICT in the non-core foundation subjects'. It also identified difficulties amongst trainers in applying use of ICT in their teaching. Estyn also highlighted that there was limited access to Welsh medium ICT resources in higher education institutions and schools. The Committee received views, both evidenced based and anecdotal, to support these findings, which were also reinforced by the Expert Adviser in his report. The Committee recommends that Estyn should be remitted to expand its review of the ICT curriculum in Initial Teacher Training institutions. Estyn should be asked to provide a comprehensive report together with recommendations to the Minister on its findings as soon as is practicable. 
It is the role of the Higher Education Funding Council Wales (HEFCW) to fund and accredit ITT in Wales. The Committee is aware of the considerable investment HEFCW has made over the last two years to support the education departments which provide ITT to strengthen their ICT. The Committee acknowledges that HEFCW and Estyn have liased closely and Estyn's inspection reports are helping to inform further work in this area. The Committee recommends that the Higher Education Funding Council Wales should continue with this work and be invited to investigate the possibility of seconding teachers, on time limited contracts, to reinforce the delivery of the ICT component in ITT institutions. We also consider that the practitioner fellows concept could be used to the same purpose.

The acquisition of ICT skills is an on going process, therefore consideration of the continued professional development of teachers should be addressed. Teachers face a major challenge not only in acquiring ICT skills but in increasing their confidence to the point where they can be innovative in developing ways of integrating technologies into the learning and teaching setting. The Committee invites the Minister to consult on how this work can be taken forward. It is imperative that a vacuum in ICT training does not occur when the current programme of New Opportunity Fund (NOF) supported training ends. The Committee recommends that the National Assembly should seek to influence the NOF planners to initiate a staff development programme for teachers to build on the existing NOF training programme.

The Committee heard much about the changing role of the teacher and the impact ICT would have on it. It accepts that training is an important issue but it is also about attitudes and learning environments where the open, imaginative use of ICT is both possible and encouraged. Teachers should be given the opportunity to explore the potential of ICT in day to day teaching either individually or in groups.

\section{Content}

In order to ensure that the ICT strategy fulfils the potential of raising educational standards and attainment in Wales, it is imperative that the content to support this is readily accessible. This content needs to be of the highest quality and relevant to the delivery of the curriculum in both Welsh and English. The Committee heard much concern at the dearth of quality content, in particular in the Welsh language. There was some evidence from LEAs that amongst their teaching staff there was good work being done, but this was locally based and in the main dependant on an individual teacher to take it forward with little or no support. 
The Committee considered the role that BECTA had played in developing the National Grid for Learning in Wales and concluded that there needed to be a more proactive role taken in Wales. The National Curriculum in Wales was different to that in England and therefore specific material needed to be developed to support teachers. This was particularly true of Welsh language content. The availability of English language content is considerable when one takes into account the resources already available on the Internet. This is not the case for Welsh language content. The Committee agreed that a strategic approach should be taken to the development of content in both languages and in order to ensure that this occurred it recommends that National Grid for Learning, Cymru (NGfL, Cymru) be established as a matter of urgency. The Minister for Education and Life-Long Learning accepted this recommendation at the Committee's meeting on 8th November.

The NGfL, Cymru would be responsible for developing the National Grid for Learning in Wales. This would involve the identification of resources that are currently available, identifying the gaps in provision and working with both the public and private sectors to address those gaps. It was suggested that NGfL, Cymru should be given the domain name 'www.taliesin.gov.uk' as a less cumbersome title than National Grid for Learning, Cymru and one that acknowledges the Welsh heritage. An application to register this name has been submitted.

There are already a number of networks serving education and NGfL, Cymru should work to establish links with these. They include the existing National Grid for Learning managed by BECTA, the Scottish site managed by Learning and Teaching, Scotland and the Further and Higher Education network - JANET. There are of course other examples from across the world which are accessible through the use of the Internet.

The Committee was impressed with the information it received about the work of SCET. The Committee would wish to see NGfL, Cymru develop a similar proactive approach in Wales to the development of content. NGfL, Cymru will need to work to establish a partnership approach to this, working with teachers, local education authorities and the private sector. The good work being done in schools by teachers has already been mentioned, this should be encouraged and supported. The Committee recommends that an e-material Innovation Fund be established to assist with the development of digital content in Wales. Such a fund should be applied in conformity with proper procurement disciplines and with regard to copyright laws. The Minister is invited to consider what appropriate arrangements need to be made to administer such a fund. 
It will also need to work closely with ACCAC to ensure that the content being delivered is relevant to the curriculum. It is also important that the quality of the content is rigorous enough to meet the needs of teachers and to this end the advice and approval of both Estyn and ACCAC must be sought. The role of ICT in the assessment of pupils through examinations is one that will need to be considered and ACCAC, Estyn, NGfL, Cymru and the examining bodies will wish to take this forward jointly.

The standard and relevance of content is key and the Committee noted that in both Scotland and Ireland their curriculum authorities had after an initial period formally joined with their National Grid for Learning teams in order to ensure the seamless delivery of the curriculum. NGfL, Cymru must be in step with and informed by ACCAC's commissioning process so that unnecessary duplication is avoided which could impose a costly bureaucratic burden on schools and teachers. The Committee recommends that the Minister takes advantage of the quinquennial review of the remit of ACCAC to explore and, if thought appropriate, determine long-term arrangements for the management of ICT curricular development in Wales.

There is a great deal of potential for developing co-operation with other Celtic countries on the Welsh language content of the National Grid for Learning. The advent of DVD technology means that one software package can be produced with several language tracks. The Scottish and Irish are already looking to develop joint ventures using European Structural Funds to support them. Wales should become a proactive force within this development. NGfL, Cymru could be given the responsibility of taking this forward. The potential to develop curriculum content in other languages should not be overlooked and the opportunities to develop cooperative ventures in this area should be taken when they arise.

There are many good examples of partnership working in the public sector and these could be developed in areas such as software development and evaluation. The inclusion of the private sector and software houses in this area could result in the production of high quality ICT resources which may not be a consumer winner but appropriate for schools. NGfL, Cymru could lead in such ventures.

NGfL, Cymru will have an important role in identifying and disseminating good practice in the use of digital materials by teachers. In the previous section on competency the changing role of the teacher was mentioned. NGfL, Cymru will have an important role in supporting teachers in the classroom in using ICT. It follows therefore that it should also be involved in supporting the training of new teachers and of continued professional development. The development of content and its use in the classroom should be seen as complementing each other and the 
work on developing the competency and confidence of teachers should also been seen as complementary. In order to assist this process NGfL, Cymru should also have responsibility for developing and maintaining the Virtual Teachers Cymru site.

\section{Conclusion}

The way forward on many of these issues must be through effective partnerships. These can work at many different levels from the large organisation on a national basis contributing to procurement; schools and local businesses working together perhaps in providing advice and support on ICT issues; the school and home in helping to support pupils by informing parents of what is happening; and involving parents in training events within the community by sharing resources and widening access to ICT thereby supporting life-long learning.

In developing the strategy the Committee also expressed its concern that the socalled digital divide should not be allowed to develop in Wales. The gap between those with the necessary ICT skills to secure good quality work and those without these skills should not be allowed to develop. This means a commitment to ensuring that all children have the opportunity to acquire the necessary skills while they are in education. The gap could be exacerbated if access to personal computers is not made possible outside school hours. This is where the opportunities for developing community ICT resources should be encouraged. The Committee suggests that the Minister seeks the advice of the Task Force on ways of ensuring that children and young people are not disenfranchised as a consequence of the increasing importance of ICT in the delivery of education and development of skills. This is a very important issue in Wales where social inclusion is a key principle underpinning government policy.

There is evidence that ICT is often seen as a 'boys' subject and that girls may engage less positively with it. This could become a major issue as we move to greater use of ICT in the delivery of the curriculum in schools. This must be addressed at the outset and such measures as how ICT is used by teachers in the delivery of the curriculum should be considered when designing teacher training courses and in the presentation of content on the NGfL, Cymru. 


\section{Chapter 4: Funding}

The Committee recognises that the implementation of this strategy will require an intensive investment in people and organisations as well as in hardware and software. Initial investment in hardware will be substantial, as will be the investment in training and professional development of teachers, and the infrastructure implications for schools and classrooms. The potential to see this investment result in an improvement in the quality of teaching and learning will represent greater value for money in a very real sense and hence be a genuine educational investment.

\section{National Assembly for Wales}

Until the results of the audit are received it will be difficult to place an accurate figure on the cost of delivering the strategy. The Committee has recommended earlier in this report that an audit be undertaken of ICT in schools. This should inform the basis of costing the strategy.

The costs of establishing the three bodies were included in budget provision for 2001-2002. NGfL, Cymru would continue after the initial three year period when it would be found a permanent host organisation at the appropriate time and taking account of the quinquennial review of ACCAC. The costs for supporting NGfL, Cymru should be transferred to the host organisation at the appropriate time.

\section{Private sector support}

There was much potential for the private sector to be involved in a number of ways in the delivery of the strategy. The Task Force would be remitted to identify private sector partners and identify with them ways in which they could contribute to the strategy such as by seconding staff to the Task Force, funding specific projects and assisting in the trialing of new technologies within schools.

\section{European funding}

The strategy emphasises the need for the ICT in Schools strategy to be seen as part of the wider picture of developing and improving the skills of everyone. One way this can be achieved is by integrating the provision of ICT in schools into the wider accessibility of ICT in the community. Schools and LEAs should be encouraged to work with partners in the community and in business to develop projects that can qualify for European monies. To help this process the Task Force should identify a lead person who can be a point of contact for schools and LEAs seeking help and information about the best way of developing eligible projects. 


\section{Chapter 5: Monitoring and Evaluation}

In order to monitor this policy, the Committee wishes to have the following information:

- the data from the audit so that a baseline can be established; and

- a detailed implementation plan with targets and time-scales.

It will then, as part of the Committee's annual scrutiny of expenditure and performance, include an item on progress in the implementation plan.

The areas to be examined in the scrutiny session will reflect the key areas and targets identified in this report. The Committee may also invite comments from LEAs, ADEW, the Task Force and NGfL, Cymru as to their perception of progress. Estyn and ACCAC will also be asked for their views when they report to the Committee in the normal course of business.

This framework can be developed into a coherent national strategy for the teaching and learning of ICT in schools in Wales. The Minister may wish to consider whether the impact of the national strategy should be the subject of a detailed research study. Such a study could provide evidence-based information on the intermediate impact of the policy on the development of pupils' ICT skills and associated learning skills, the integration of ICT into the education system at both primary and secondary levels, the impact on classroom teaching and pedagogy, amongst others. On a long-term basis it could look at academic and vocational achievements taking into account Estyn inspection reports.

The contextual impact of the policy needs to be understood in terms of how it impacts on the education provision for children across all age ranges and the development of ICT skills in young people which are appropriate to the needs of the Welsh economy, research could aid that analysis. Key indicators to measure such things as computer/pupil ratios, pupil/computer contact time per week could help with the analysis of social inclusion issues, and if these were broken down on a gendered basis it would be helpful in identifying any gender issues that might be developing. Comparisons with best practice elsewhere could be drawn so that progress in Wales can be benchmarked. 


\section{Chapter 6: Conclusion}

We are already in the third generation of ICT, it has moved from floppy discs, through CD-ROM technology to the Internet and we are already seeing tomorrow's technology evolving in the form of digital televisions and the combining of digital and Internet technology. These are exciting times and with these developments come both challenges and opportunities. We must grasp those opportunities and support the young people who are in education to maximise upon them. We must however not be blind to the challenges and this strategy seeks to raise awareness and suggest ways in which they can be addressed.

The effective use of ICT involves much more than hardware itself. Most critically it involves the application of high quality software in the interests of the learners. In large measure it is about enlarging the ethos of schools and indeed other education institutions.

We are not looking towards a revolution in education and teaching but rather towards sustained and dynamic evolution whose momentum must be deliberately and constantly maintained.

With that view the Committee commends this report to the National Assembly and to the Minister for Education and Life-Long Learning. 


\section{Annex A}

\section{Advisory Panel for ICT in Schools}

To provide advice to the Minister on the development and delivery of the ICT Strategy for ICT in Schools. The membership of the Panel will be drawn so as to represent the interests of the teaching profession; curriculum development; the training of teachers; content development; private sector interests; local education authorities and others as the Minister determines.

The Panel should be established and remitted for 3 years. The Secretariat should be provided from the Information and Communication Technology Task Force.

\section{Information and Technology Task Force}

To be established for a period of three years and will provide the momentum for delivering the ICT Strategy in Schools. It should have responsibility for:

- developing a national procurement agreement;

- identifying and accessing funding sources from both public and private sectors;

- identifying and establishing areas in which the education sector in Wales could collaborate e.g. shared networks;

- identifying and establishing joint initiatives with the private sector;

- exploring the potential of establishing a personal computer re-cycling scheme;

- advising on equality of access issues; and

- providing secretarial support for the Advisory Panel.

\section{National Grid for Learning, Cymru (taliesin.gov.uk)}

Establish this body for an initial period of three years working alongside the Task Force. After this initial period the NGfL, Cymru will continue but will be located in an appropriate host organisation.

It will require staff with high level ICT skills and knowledge of the education sector. Its main tasks will be to: 
- identify curriculum content in both English and Welsh and develop it so that it is suitable for ICT application;

- commission new curriculum content where gaps are identified;

- administer the Innovative Schools Fund initiative;

- identify and encourage private sector development of content;

- provide advice on computer and infrastructure issues, including new technological developments;

- develop and design web-sites, including support to schools and LEAs;

- liase with ACCAC, Estyn and other bodies on content issues including the quality assurance aspects;

- provide advice and support to teacher training institutions and develop and maintain the Virtual Teachers Cymru site;

- catalogue and metadata the content; and

- take a lead in developing multi-lingual potential of DVD technology and funding available under EC initiatives.

\section{Structure}

Minister for Education and Life-Long Learning

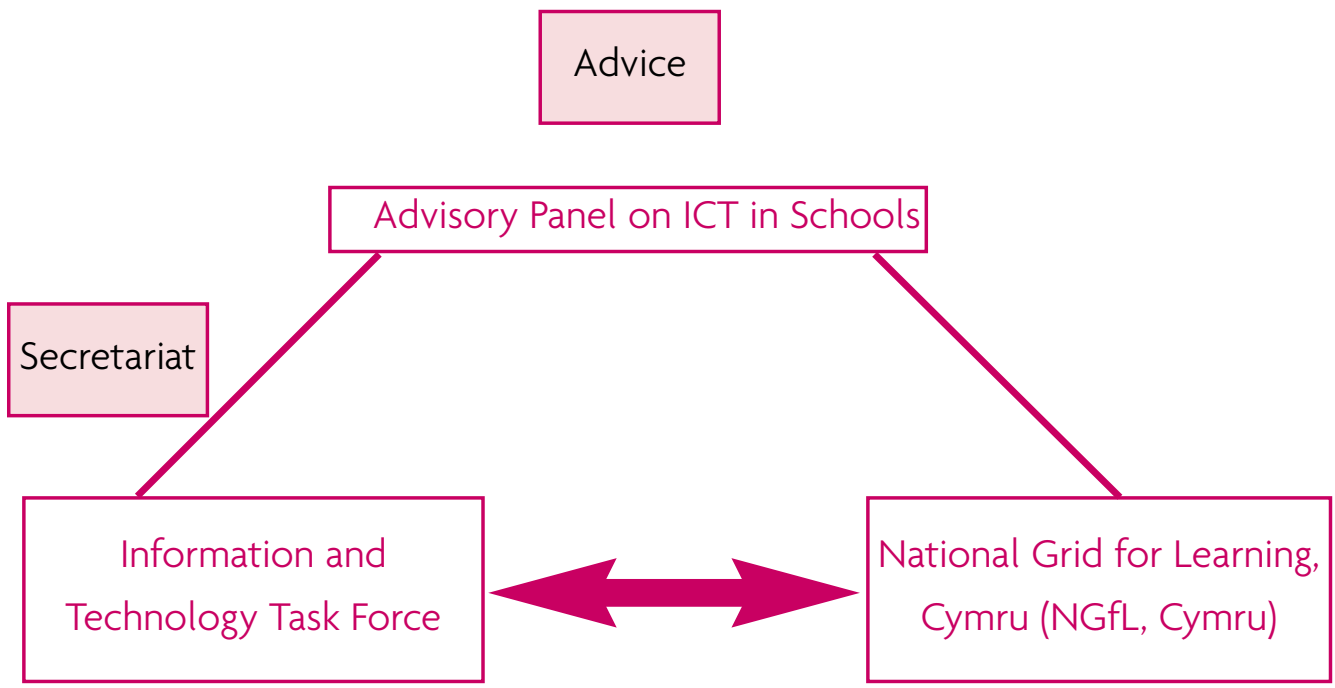

